\title{
Speculative housing markets and rent control: insights from nonlinear economic dynamics
}

\author{
Noemi Schmitt ${ }^{1} \cdot$ Frank Westerhoff $^{1}$ (D)
}

Received: 31 March 2020 / Accepted: 8 December 2020 / Published online: 7 January 2021

(c) The Author(s) 2021

\begin{abstract}
We propose a novel housing market model to explore the effectiveness of rent control. Our model reveals that the expectation formation and learning behavior of boundedly rational homebuyers, switching between extrapolative and regressive expectation rules subject to their past forecasting accuracy, may create endogenous housing market dynamics. We show that policymakers may use rent control to reduce the rent level, although such policies may have undesirable effects on the house price and the housing stock. However, we are also able to prove that welldesigned rent control may help policymakers to stabilize housing market dynamics, even without creating housing market distortions.
\end{abstract}

Keywords Housing market dynamics · Expectation formation and learning behavior · Rent control $\cdot$ Steady state, stability and out-of-equilibrium analysis

JEL Classification D84 · G12 $\cdot$ R21

\section{Introduction}

Galbraith (1994), Kindleberger and Aliber (2011) and Glaeser (2013) demonstrate that boom-bust housing market dynamics may be quite harmful to the real economy. Obviously, the instability of housing markets may also affect the rental market. To provide affordable rental housing, policymakers may control the rental market, e.g., by placing caps on rent increases or even by freezing rents, as reported by Arnot (1995), Turner and Malpezzi (2003), Autor et al. (2014) and Metcalf (2018). When it comes to explaining what really causes the boom-bust behavior of housing markets, Case and Shiller (2003), Case et al. (2012) and Shiller (2015) stress that homebuyers' extrapolative expectations are major drivers of endogenous house

Frank Westerhoff

frank.westerhoff@uni-bamberg.de

1 Department of Economics, University of Bamberg, Feldkirchenstrasse 21, 96045 Bamberg, Germany 
price fluctuations. However, it is important to note that economic agents are not irrational. As argued by Hommes (2013), economic agents usually rely on a limited set of plausible rules to form expectations and select between them according to their evolutionary fitness. Against this background, the goal of our paper is twofold. First, we develop a novel expectations-driven housing market model to enhance our understanding of housing market dynamics. Second, we use our model to explore the extent to which policymakers can influence housing markets by imposing rent control.

We may summarize the setup of our (unregulated) housing market model as follows. There is a single price for housing that is paid by all homebuyers. The house price is determined via an intertemporal no-arbitrage condition and equals the discounted value of the next period's expected house price and rent payments. To form their expectations, homebuyers use a mix of extrapolative and regressive expectation rules. The weights of these expectation rules, modeled via exponential replicator dynamics, depend on their evolutionary fitness, measured in terms of squared prediction errors. While the extrapolative expectation rule is free, the regressive expectation rule is costly. The (unregulated) rent level decreases with the existing stock of houses. The housing stock, in turn, is subject to depreciation and new housing construction, where new housing construction depends positively on past house prices. Our model, equivalent to a six-dimensional nonlinear map, possesses one economically meaningful steady state at which the house price corresponds to the discounted value of future rent payments. We show that this steady state may become unstable due to a Neimark-Sacker bifurcation if homebuyers extrapolate past house price changes strongly. We then observe oscillatory fluctuations of the house price, the housing stock and the rent level. As it turns out, we can also use our model to study the effectiveness of rent control. Most importantly, we are able to prove analytically that well-designed rent control allows policymakers to stabilize housing markets without creating welfare-hampering distortions. Needless to say, ill-designed rent control programs may achieve the opposite.

Our paper is organized as follows. In Sect. 2, we relate our paper more closely to the existing literature. In Sect. 3, we develop our housing market model. In Sects. 4 and 5, we present our main analytical and numerical results, respectively. In Sect. 6, we conclude our work and point out some avenues for future research. Appendix A, B and C provides a detailed formal analysis of our model as well as a number of additional robustness checks.

\section{Literature review}

Our paper builds on the work by Dieci and Westerhoff (2016) and Schmitt and Westerhoff (2019). Dieci and Westerhoff (2016) combine Poterba's $(1984,1991)$ housing market framework, comprising explicit relations between the house price, the housing stock and the rent level, with a quite parsimonious approach that captures the expectation formation and learning behavior of boundedly rational homebuyers, as put forward by Day and Huang (1990), de Grauwe et al. (1993) and He and Westerhoff (2005). In particular, the expectation formation and learning part of their 
model assumes that homebuyers, relying on extrapolative and regressive expectation rules to forecast future house prices, increasingly turn to the regressive expectation rule as house prices disconnect from their fundamental values, simply because they fear that the housing market bubble will burst. The simplicity of the model by Dieci and Westerhoff (2016), formally equivalent to a two-dimensional nonlinear map, allows deep analytical insights into the intricate interplay between real and speculative forces. Moreover, simulations reveal that their model is able to generate cyclical housing market dynamics with lasting periods of overvaluation and overbuilding, as observed in many real housing markets.

Schmitt and Westerhoff (2019) combine Poterba's $(1984,1991)$ housing market model with the heuristic switching approach by Brock and Hommes (1997, 1998), capturing in more detail homebuyers' expectation formation and learning behavior. To be more precise, homebuyers switch between extrapolative and regressive expectation rules subject to their forecasting accuracy. As it turns out, their model is able to replicate key properties of housing market dynamics, including its shortrun momentum, long-run mean reversion and excess volatility. More importantly, however, Schmitt and Westerhoff (2019) analytically prove that such dynamics can only occur if extrapolative expectations are heavy-handed. Policy applications based on these two frameworks are provided, for instance, by Martin et al. (2020a, b). The former paper studies whether central banks may stabilize the housing market by adjusting the interest rate, while the latter paper explores the extent to which policymakers can stabilize housing markets by altering the tax code.

Our paper deviates from this line of research in at least two important dimensions. First, we employ exponential replicator dynamics to capture homebuyers' rule selection behavior. Exponential replicator dynamics entails a herding behavior among homebuyers and has, in contrast to the heuristic switching approach, alternative steady-state implications. As we will see, a key property of exponential replicator dynamics is that all homebuyers use the expectation rule that produces the highest evolutionary fitness at the (economically meaningful) steady state, i.e., no homebuyer will pick an inferior expectation rule when the dynamics is at rest. Second, we use our model to explore possible consequences of rent control. As far as we are aware, no other papers apply expectations-driven housing market models to study the steady-state, stability and out-of-equilibrium effects of rent control.

Further contributions in this blossoming research field, focusing on the expectation formation and learning behavior of boundedly rational homebuyers, include Bao and Hommes (2019), Bolt et al. (2019), Burnside et al. (2016), Campisi et al. (2018), Dieci and Westerhoff (2012, 2013), Eichholtz et al. (2015), Diks and Wang (2016), Kouwenberg and Zwinkels (2014) and Glaeser and Nathanson (2017). Dieci and $\mathrm{He}(2018)$ review parts of the literature.

\section{The model}

Let us turn to our model. As in Schmitt and Westerhoff (2019), there is a single price of housing paid by all homebuyers. Moreover, the house price $P_{t}$ is derived from an intertemporal no-arbitrage condition and equals the discounted value of the 
next period's expected house price $E_{t}\left[P_{t+1}\right]$ plus rent payments $R_{t}$, due at the end of the period. Formally, the house price in period $t$ obeys

$$
P_{t}=\frac{E_{t}\left[P_{t+1}\right]+R_{t}}{1+r+\delta}
$$

where $r>0$ stands for the risk-free interest rate and $0<\delta<1$ denotes the housing depreciation rate. Clearly, (1) implies that the house price adjusts such that riskneutral homebuyers are indifferent between investing their wealth in a safe asset, guaranteeing the risk-free interest rate $r$, and investing in the housing market, yielding the expected gain $\left(E_{t}\left[P_{t+1}\right]+R_{t}-(1+\delta) P_{t}\right) / P_{t}$. Suppose, for instance, that the interest rate is lower than the expected gain, i.e., $r<\left(E_{t}\left[P_{t+1}\right]+R_{t}-(1+\delta) P_{t}\right) / P_{t}$. Then, homebuyers will increase their housing demand up to the point where the resulting house price increase is such that the no-arbitrage condition (1) holds once again. $^{1}$

Homebuyers have the choice between different types of expectation rules and select between them depending on their evolutionary fitness. For analytical tractability, we concentrate on two representative expectation rules. In line with empirical and experimental evidence (Menkhoff and Taylor 2007; Hommes 2011), we assume that homebuyers can choose between an extrapolative expectation rule and a regressive expectation rule. Homebuyers' house price expectations are defined by

$$
E_{t}\left[P_{t+1}\right]=W_{t}^{E} E_{t}^{E}\left[P_{t+1}\right]+W_{t}^{R} E_{t}^{R}\left[P_{t+1}\right]
$$

where $E_{t}^{E}\left[P_{t+1}\right]$ and $E_{t}^{R}\left[P_{t+1}\right]$ represent predictions generated by the extrapolative and the regressive expectation rule, respectively, and $W_{t}^{E}$ and $W_{t}^{R}$ represent their corresponding weights.

The extrapolative expectation rule presumes that the current house price trend will continue. Inspired by Chiarella (1992) and Chiarella et al. (2006), we formalize the extrapolative expectation rule by

$$
E_{t}^{E}\left[P_{t+1}\right]=P_{t-1}+\eta \arctan \left[\frac{\chi}{\eta}\left(P_{t-1}-P_{t-2}\right)\right],
$$

where $\eta=\frac{2 \kappa}{\pi}>0$ and $\chi>0$ determine homebuyers' extrapolation strength. Note that the latter term of (3) represents an S-shaped function that is bounded in the interval $(-\kappa, \kappa)$, reflecting homebuyers' tendency to react more cautiously to larger house price changes. ${ }^{2}$ The regressive expectation rule predicts that the house price will converge toward its fundamental value. Let $F$ denote homebuyers' perception of

\footnotetext{
1 Dieci and Westerhoff (2016) derive an explicit expression for homebuyers' housing demand via a standard one-period mean-variance framework. Their house price equation becomes equivalent to ours if homebuyers' risk aversion approaches zero.

2 Note that our analytical results (see Proposition 1) also hold when homebuyers rely on the linear extrapolative expectation rule $E_{t}^{E}\left[P_{t+1}\right]=P_{t-1}+\chi\left(P_{t-1}-P_{t-2}\right)$, with $\chi>0$. However, the nonlinear extrapolative expectation rule (3) produces more reasonable bounded housing market dynamics. The same is true for the regressive expectation rule (4).
} 
the true fundamental house price. Using again an S-shaped function, we express the regressive expectation rule by

$$
E_{t}^{R}\left[P_{t+1}\right]=P_{t-1}+\theta \arctan \left[\frac{\phi}{\theta}\left(F-P_{t-1}\right)\right],
$$

where $\theta=\frac{2 \lambda}{\pi}>0$ and $0 \leq \phi \leq 1$ capture homebuyers' expected mean reversion speed. ${ }^{3}$ Importantly, homebuyers' perception of the fundamental house price may be right or wrong, i.e., $F$ may deviate from the true steady-state value of the house price. ${ }^{4}$ As is common in this line of research, homebuyers predict the house price for period $t+1$ at the beginning of period $t$, based on information available at the end of period $t-1$.

The expectation rules' evolutionary fitness depends negatively on squared prediction errors and possible costs arising from their use. Hence, we have

$$
A_{t}^{E}=-\mu\left(P_{t-1}-E_{t-2}^{E}\left[P_{t-1}\right]\right)^{2}
$$

and

$$
A_{t}^{R}=-\mu\left(P_{t-1}-E_{t-2}^{R}\left[P_{t-1}\right]\right)^{2}-\sigma
$$

where $\mu$ is a positive parameter that measures the sensitivity of the expectation rules' evolutionary fitness with respect to their past forecasting accuracy. In line with Brock and Hommes (1997, 1998), the extrapolative expectation rule is free, but the more sophisticated regressive expectation rule, requiring the computation of $F$, incurs positive information costs $\sigma .^{5}$ We may also regard parameter $\sigma$ as a behavioral bias in favor of the simpler extrapolative expectation rule, as discussed in Anufriev et al. $(2016,2018)$.

We use the exponential replicator dynamics approach by Hofbauer and Sigmund (1988) and Hofbauer and Weibull (1996) to determine the weights of the two expectation rules. Accordingly, we have

$$
W_{t}^{E}=\frac{W_{t-1}^{E} \exp \left[\varepsilon A_{t}^{E}\right]}{W_{t-1}^{E} \exp \left[\varepsilon A_{t}^{E}\right]+W_{t-1}^{R} \exp \left[\varepsilon A_{t}^{R}\right]}
$$

and

$$
W_{t}^{R}=\frac{W_{t-1}^{R} \exp \left[\varepsilon A_{t}^{R}\right]}{W_{t-1}^{E} \exp \left[\varepsilon A_{t}^{E}\right]+W_{t-1}^{R} \exp \left[\varepsilon A_{t}^{R}\right]},
$$

\footnotetext{
${ }^{3}$ Note that $\phi=0$ implies naïve expectations, while $\phi=1$ and $\lambda \rightarrow \infty$ entail pure fundamentalist beliefs.

4 At first sight, this may appear to be a minor detail. However, computing the true fundamental house price correctly is nearly impossible in real markets. Our model does not rely on this assumption; homebuyers may be right or wrong with respect to their perception of the true fundamental house price.

5 In Appendix B, we study the case $\sigma=0$.
} 
where parameter $\varepsilon>0$ denotes homebuyers' intensity of choice. For our purpose, the exponential replicator dynamics approach has the following three desirable economic implications. First, homebuyers tend to choose the expectation rule that has the higher evolutionary fitness. Second, the impact of the expectation rule that yields better predictions increases with homebuyers' intensity of choice. Third, homebuyers display (a mild form of) herding behavior. ${ }^{6}$

While first-generation rent control policies simply suggest freezing the rent level, second-generation rent control policies at least recommend allowing for some kind of rent flexibility (Arnot 1995; Turner and Malpezzi 2003; Autor et al. 2014 and Metcalf 2018). In general, it seems plausible to assume that the rent level will depend negatively on the existing stock of houses, say $\tilde{R}_{t}=\alpha-\beta H_{t}$, with $\alpha, \beta>0$. In this paper, we consider a policy according to which policymakers restrict the evolution of the rent level as follows:

$$
R_{t}=R^{G}+\tau\left(\tilde{R}_{t}-R^{G}\right)=(1-\tau) R^{G}+\tau\left(\alpha-\beta H_{t}\right),
$$

where $R^{G}$ stands for policymakers' target rent level and $0 \leq \tau \leq 1$ is a control parameter. With the rent control policy (9), policymakers seek to keep the rent level near the target rent level and, thereby, also to tame changes in the rent level. Let us consider a few examples. For $\tau=1$, the rent level, given by $R_{t}=\alpha-\beta H_{t}$, is completely flexible, as in Dieci and Westerhoff (2016). ${ }^{7}$ For $\tau=0$, the rent level is fixed and equal to $R_{t}=R^{G}$, as is the case in first-generation rent control policies. For $\tau=0.5$, the regulated rent level is given by the average of policymakers' target rent level and the rent level that would result in an unregulated environment. Accordingly, lower values of the control parameter $\tau$ mean tighter regulation of the rental market. ${ }^{8}$

Finally, the housing stock evolves as

$$
H_{t}=I_{t}+(1-\delta) H_{t-1},
$$

where new housing construction depends positively on the past house price, i.e.

$$
I_{t}=\gamma P_{t-1},
$$

with $\gamma>0$. Note that new housing construction is consistent with the assumptions that housing constructors face a one-period production lag, maximize expected

\footnotetext{
${ }^{6}$ To see this, note that (7) may also be expressed by $W_{t}^{E}=W_{t-1}^{E} /\left(W_{t-1}^{E}+\left(1-W_{t-1}^{E}\right) \exp \left[\varepsilon\left(A_{t}^{R}-A_{t}^{E}\right)\right]\right)$. As $W_{t-1}^{E}$ approaches zero or one, the weights of the two expectation rules in period $t$ depend less strongly on the difference of their evolutionary fitness and more strongly on their past popularity. See Dindo and Tuinstra (2011), Bischi et al. (2015), Kopel et al. (2014) and Schmitt et al. (2017) for further applications of the exponential replicator dynamics approach.

${ }^{7}$ Dieci and Westerhoff (2016) motivate this relation as follows. Market clearing in the rental market implies that the demand for housing services, $D_{t}=a-b R_{t}$, with $a, b>0$, is equal to the supply of housing services, $S_{t}=c H_{t}$, with $c>0$, that is $D_{t}=S_{t}$. It immediately follows that $R_{t}=\alpha-\beta H_{t}$, with $\alpha=\frac{a}{b}>0$ and $\beta=\frac{c}{b}>0$. Note that the whole housing stock enters the rental market, i.e., all homebuyers offer their houses on the rental market.

${ }^{8}$ In Appendix C, we explore the effects of a related rent control policy, assuming that policymakers only activate (9) in periods when the rent level exceeds a critical threshold.
} 
profits subject to a quadratic cost function, i.e., $C_{t}=\frac{1}{2 \gamma} I_{t}^{2}$ and form naïve expectations. ${ }^{9}$ Moreover, lower values of $\gamma$ imply higher building costs and a more sluggish housing supply. See Bao and Hommes (2019) for a similar modeling setup of new housing construction.

\section{Analytical results}

In Appendix A, we show that the dynamics of our model is driven by the iteration of a six-dimensional nonlinear map. Moreover, our model possesses two (boundary) steady states. While one of the boundary steady states is economically meaningful and locally asymptotically stable for a certain part of the parameter space, the other boundary steady state is always unstable. ${ }^{10}$ The following proposition summarizes our main analytical results (an overbar denotes steady-state quantities):

Proposition 1 The model's economically meaningful steady state, implying that $\bar{P}=\frac{\left((1-\tau) R^{G}+\tau \alpha\right) \delta}{(r+\delta) \delta+\tau \beta \gamma}, \quad \bar{H}=\frac{\gamma}{\delta} \bar{P}=\frac{\left((1-\tau) R^{G}+\tau \alpha\right) \gamma}{(r+\delta) \delta+\tau \beta \gamma}, \quad \bar{R}=(r+\delta) \bar{P}=\frac{(r+\delta) \delta\left((1-\tau) R^{G}+\tau \alpha\right)}{(r+\delta) \delta+\tau \beta \gamma} \quad$ and $\overline{\mathrm{W}}^{\mathrm{E}}=1$, becomes unstable if the stability condition $\chi<1+r+\delta-\tau \frac{(r+\delta) \delta+\tau \beta \gamma}{r+\delta(2-\chi(1-\delta))}$ is violated. Moreover, the loss of stability is associated with a Neimark-Sacker bifurcation.

Proposition 1 deserves some discussion. Let us start with the model's economically meaningful steady state:

- The house price, the housing stock and the rent level depend only on the housing market's real side. Put differently, the model's behavioral parameters, characterizing homebuyers' expectation formation and learning behavior, are irrelevant for the determination of $\bar{P}, \bar{H}$ and $\bar{R}$.

- The model's real parameters have straightforward and important steady-state implications. Let us consider one example. Suppose that the central bank increases the interest rate. Higher interest rates lessen the attractiveness of the housing market as an investment opportunity for homebuyers. As a result, the house price will decrease. Lower house prices, in turn, dampen the construction of new housing, and, consequently, the housing stock decreases, an outcome that increases the rent level (except for $\tau=0$ ).

9 In Dieci and Westerhoff (2012), housing constructors have perfect-foresight expectations. Campisi et al. (2018) assume that housing constructors rely on a mix of perfect foresight and naïve expectations. However, Martin et al. (2020a) demonstrate that models with larger production lags may produce quite similar housing market dynamics as models in which new housing construction is given by (11).

10 At the second boundary steady state, all homebuyers rely on the regressive expectation rule. Since the steady-state fitness of the costly regressive expectation rule is always lower than the steady-state fitness of the free extrapolative expectation rule, even if homebuyers perceive the true fundamental house price correctly, the second boundary state is economically uninteresting. Eventually, homebuyers should realize their mistakes and switch to the extrapolative expectation rule. This is also the reason why this steady state is unstable. 
- Moreover, the model's economically meaningful steady state implies that $\bar{W}^{E}=1$, i.e., all homebuyers use the free extrapolative expectation rule. Note that this expectation rule makes no steady-state prediction errors. It immediately follows from the house price Eq. (1) that $\bar{P}=\frac{R}{r+\delta}$. Accordingly, the house price corresponds to the discounted value of future rent payments, as already mentioned by Poterba $(1984,1991)$. The term $r+\delta$ is usually regraded as the user costs of housing.

- Importantly, if policymakers set the target rent level equal to the rent level that would prevail in an unregulated rental market, the steady-state levels of the house price, the housing stock and the rent level will be unaffected by rent control. More formally, for $R^{G}=\bar{R}=\frac{(r+\delta) \delta \alpha}{(r+\delta) \delta+\beta \gamma}$, we obtain $\bar{P}=\frac{\alpha \delta}{(r+\delta) \delta+\beta \gamma}$ and $\bar{H}=\frac{\alpha \gamma}{(r+\delta) \delta+\beta \gamma}$. In the following, we call this policy a well-designed rent control policy, since $\bar{P}, \bar{H}$ and $\bar{R}$ correspond to their true fundamental values, and policymakers' regulation of the rental market therefore does not inflict any housing market distortions.

- Note that policymakers are able to influence the steady-state rent level by adjusting the target rent level. In particular, $\bar{R}$ decreases for lower values of $R^{G}$. Unfortunately, a lower rent level makes the housing market less attractive for homebuyers and, consequently, the house price and the housing stock will decrease, too. ${ }^{11}$ Alternatively, policymakers may decide to reduce the rent level by decreasing the control parameter $\mu$, provided that $R^{G}<\bar{R}=\frac{(r+\delta) \delta \alpha}{(r+\delta) \delta+\beta \gamma}$. As before, a reduction in the rent level depresses the house price and results in a smaller housing stock. Clearly, a smaller housing stock may not be in the interest of policymakers. $^{12}$

Let us now turn to the Neimark-Sacker stability condition ${ }^{13}$ :

- The emergence of endogenous housing market cycles requires that homebuyers form extrapolative expectations. Put differently, if homebuyers have naïve expectations, i.e., if $\chi=0$, the Neimark-Sacker stability condition will always hold.

- The model's steady state will lose its local asymptotic stability at the latest if parameter $\chi$ approaches $1+r+\delta$, provided that the economically reasonable

\footnotetext{
11 Similar steady-state effects of rent control policies are reported in Sims (2007) and Autor et al. (2014).

12 Glaeser and Luttmer (2003) discuss rent-control welfare losses that may arise due to the undersupply and misallocation of housing units. See Turner and Malpezzi (2003) for a more general cost-benefit analysis of rent control.

13 As shown in Appendix A, the economically meaningful steady state may also become unstable due to a Flip bifurcation. By giving rise to a period-two cycle, however, a Flip bifurcation is less suited to explain the oscillatory behavior of actual housing markets. Moreover, within our model framework, a Flip bifurcation necessitates a rather extreme response of the housing market's real side to changes in the rent level and the house price, which is why we focus on the much more interesting Neimark-Sacker bifurcation scenario.
} 
assumption $r+\delta<1$ holds. $^{14}$ To see this, note that the term $\tau \frac{\beta \gamma(1-\delta) \chi}{r+\delta(2-\chi(1-\delta))}$ remains positive as long as $\chi<2 /(1-\delta)$.

- Due to the term $\tau \frac{\beta \gamma(1-\delta) \chi}{r+\delta(2-\chi(1-\delta))}$, however, the loss of stability may occur before $\chi$ exceeds $1+r+\delta$. In particular, the Neimark-Sacker stability condition becomes more binding if the rental market reacts more strongly to the housing stock and/ or if new housing construction reacts more strongly to the house price.

- Fortunately, however, policymakers can stabilize the housing market by controlling the rental market: a decrease in the control parameter $\tau$ from one to zero monotonically increases the parameter domain that ensures market stability.

- Note furthermore that the Neimark-Sacker stability condition is independent of policymakers' target rent level. By adjusting $R^{G}$, policymakers can influence the steady-state quantities of $\bar{P}, \bar{H}$ and $\bar{R}$ without affecting the local asymptotic stability of the model's economically meaningful steady state. In contrast, changes of the control parameter $\tau$ affect the model's steady-state levels and stability domain, except when $R^{G}=\frac{(r+\delta) \delta \alpha}{(r+\delta) \delta+\beta \gamma}$. Setting $R^{G}=\frac{(r+\delta) \delta \alpha}{(r+\delta) \delta+\beta \gamma}$ allows policymakers to stabilize the housing market without affecting its true fundamental steady state.

As we will see, our analytical insights provide a useful orientation for the numerical analysis of our model, addressed in the next section.

\section{Numerical results}

To simulate the dynamics of our model, we have to specify its parameters. For the model's real side, we assume that $\alpha=20, \beta=0.1, \gamma=0.05, \delta=0.05, r=0.05$, $R^{G}=10$ and $\tau=\{0,0.5,1\}$. Irrespective of our choice of parameter $\tau$, we thus have $\bar{P}=100, \bar{H}=100$ and $\bar{R}=10$. Note that $R^{G}=\bar{R}$, i.e., policymakers' target rent level is equal to the rental market's true fundamental value. For the model's behavioral side, we assume that $\chi=1.07, \kappa=10, \phi=0.25, \lambda=10, F=100, \mu=1, \sigma=1$ and $\epsilon=1$. Note that homebuyers using the regressive expectation rule perceive the true fundamental house price correctly. ${ }^{15}$ Depending on policymakers' control parameters, our analytical results predict the emergence of a Neimark-Sacker

\footnotetext{
14 We would like to point out an interesting connection between our housing market model and related expectations-driven asset-pricing models. For $\beta=\gamma=\delta=\tau=0$, our stability condition boils down to $\chi<1+r$. Such a stability condition would also result in an asset-pricing model in which the dividend payments of the risky asset are given by $R^{G}$ and in which all market participants rely on extrapolative expectations, implying a steady-state risky-asset price of $\bar{P}=R^{G} / r$. See, for instance, Brock and Hommes (1998) and Schmitt and Westerhoff (2020).

15 Since information costs are positive, all homebuyers opt for the superior extrapolative expectation rule at the steady state, implying that homebuyers' perception of the true fundamental house price is irrelevant for the steady state's coordinates and its local asymptotic stability domain. Out of equilibrium, however, homebuyers' perception of the true fundamental house price may influence housing markets. Simulations reveal, for instance, that the housing market may become overvalued when (i) homebuyers favor the regressive expectation rule and (ii) overestimate the true fundamental house price.
} 

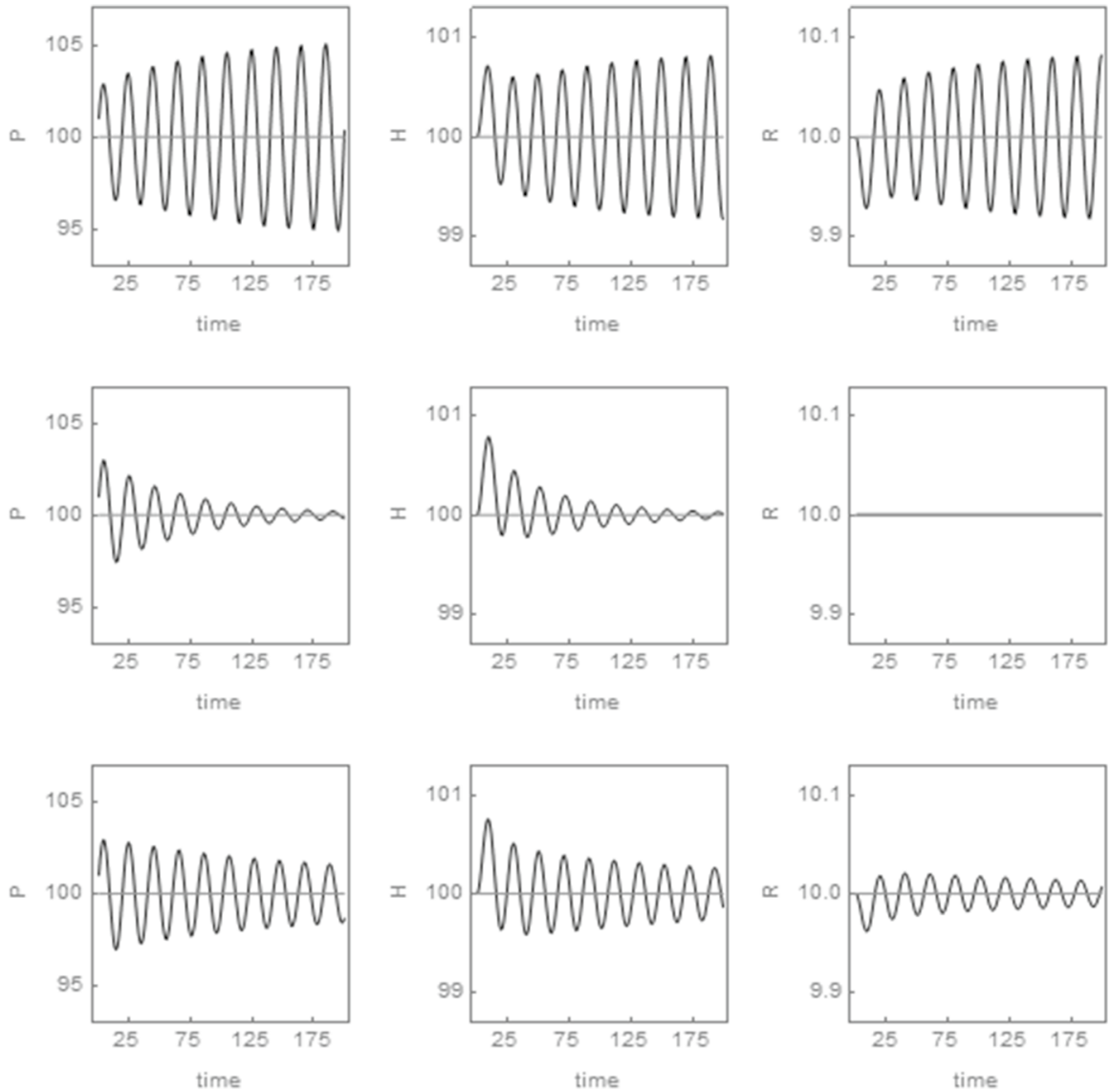

Fig. 1 Housing market dynamics in the time domain. The left panels show the evolution of house prices for flexible rents $(\tau=1)$, fixed rents $(\tau=0)$ and regulated rents $(\tau=0.5)$, respectively. The center (right) panels show the corresponding development of the housing stock (rent levels). See Sect. 5 for more details on the underlying parameter setting

bifurcation at $\chi_{\text {crit }}^{N S} \approx 1.051$ for $\tau=1$ (flexible rents), $\chi_{\text {crit }}^{N S} \approx 1.075$ for $\tau=0.5$ (regulated rents) and $\chi_{\text {crit }}^{N S}=1.1$ for $\tau=0$ (fixed rents). Our assumptions about the model parameters, e.g., the interest rate or the depreciation rate, suggest that we may regard one time step in our model as 1 year. However, we do not aim at replicating the behavior of actual housing markets in finer detail.

Figure 1 illustrates the model's dynamics for our base parameter setting. The left panels of Fig. 1 show the evolution of the house price for flexible rents $(\tau=1)$, fixed rents $(\tau=0)$ and regulated rents $(\tau=0.5)$, respectively. The center (right) panels of Fig. 1 depict the corresponding development of the housing stock (rent level). In all three cases, we introduce a one-percent shock to the house price in period $t=1$ and present the consequent dynamics for the next 200 time steps. The top line of panels in Fig. 1 indicates that our model may produce endogenous housing market 
dynamics. After a brief transient period, the house price, the housing stock and the rent level oscillate around their true fundamental steady-state values with a constant amplitude. The central line of panels in Fig. 1 suggests that a strict regulation of the rental market can stabilize the housing market. If policymakers set the target value equal to its steady-state value, then the dynamics of the housing market will die out and the house price, the housing stock and the rent level will correspond to their true fundamental steady-state values. The bottom line of panels in Fig. 1 depicts an intermediate scenario. For $\tau=0.5$, we still observe endogenous housing market dynamics, yet the amplitude of the house price, the housing stock and the rent level is lower than in the case of an unregulated rental market.

Figure 2 shows bifurcation diagrams of the house price versus homebuyers' extrapolation parameter $\chi$ for flexible rents $(\tau=1)$, fixed rents $(\tau=0)$ and regulated rents $(\tau=0.5)$, respectively. For all three scenarios, we eventually observe the onset of oscillatory housing price fluctuations. However, smaller values of policymakers' control parameter maintain the stability of the housing market for larger values of homebuyers' extrapolation parameter. Moreover, when the housing market displays endogenous dynamics, the amplitude of house price fluctuations will decrease for lower values of parameter $\tau$. Of course, the same is true for the housing stock and the rent level (not depicted),

So far, we have assumed that policymakers set the target rent level equal to the steady-state level of the unregulated housing market. However, policymakers may have reasons to deviate from this assumption, e.g., because they are influenced by certain interest groups (Fallis 1988, Arnot 1995, Epple 1998). Of course, policymakers may also misperceive the steady-state value of the unregulated rental market. Figure 3 shows bifurcation diagrams of the house price versus policymakers' control parameter for higher target rents $\left(R^{G}=11\right)$, unbiased target rents $\left(R^{G}=10\right)$ and lower target rents $\left(R^{G}=9\right)$. As can be seen, the level of the target rent has no impact on the Neimark-Sacker bifurcation value. In line with Proposition 1, the Neimark-Sacker bifurcation occurs for our parameter setting at $\tau_{c r i t}^{N S} \approx 0.587$. However, policymakers can influence the steady-state values of the house price, the housing stock and the rent level via $R^{G}$. For instance, the bottom panel demonstrates that a lower value of the target rent level reduces not only the rent level, but also the house price and the housing stock. As can furthermore be seen, a tighter regulation of the housing market, i.e., a lower value of parameter $\tau$, fosters this development. ${ }^{16}$

In Fig. 4, we show how policymakers may affect volatility, defined as $\frac{1}{T} \sum_{t=1}^{T}\left|P_{t}-P_{t-1}\right|$, distortion, defined as $\frac{1}{T} \sum_{t=1}^{T}\left|P_{t}-\bar{P}\right|$, the average rent level, defined as $\frac{1}{T} \sum_{t=1}^{T} R_{t}$, and the rent level's average absolute deviation from the target rent level, defined as $\frac{1}{T} \sum_{t=1}^{T}\left|R_{t}-R^{G}\right|$, by jointly setting parameters $\tau$ and $R^{G}$. We vary both parameters in 50 discrete steps in the range of $0 \leq \tau \leq 1$ and $9 \leq R^{G} \leq 10$,

\footnotetext{
16 Note that homebuyers misperceive the true fundamental house price in the simulations depicted in the top and bottom panels in Fig. 3. At the steady state, homebuyers' misperceptions of the true fundamental house price do not matter since they do not use the regressive expectation rule. Further simulations (not depicted) reveal that the out-of-equilibrium effects of homebuyers' misperception of the true fundamental house price are relatively mild, at least as long as misperceptions do not become too large.
} 

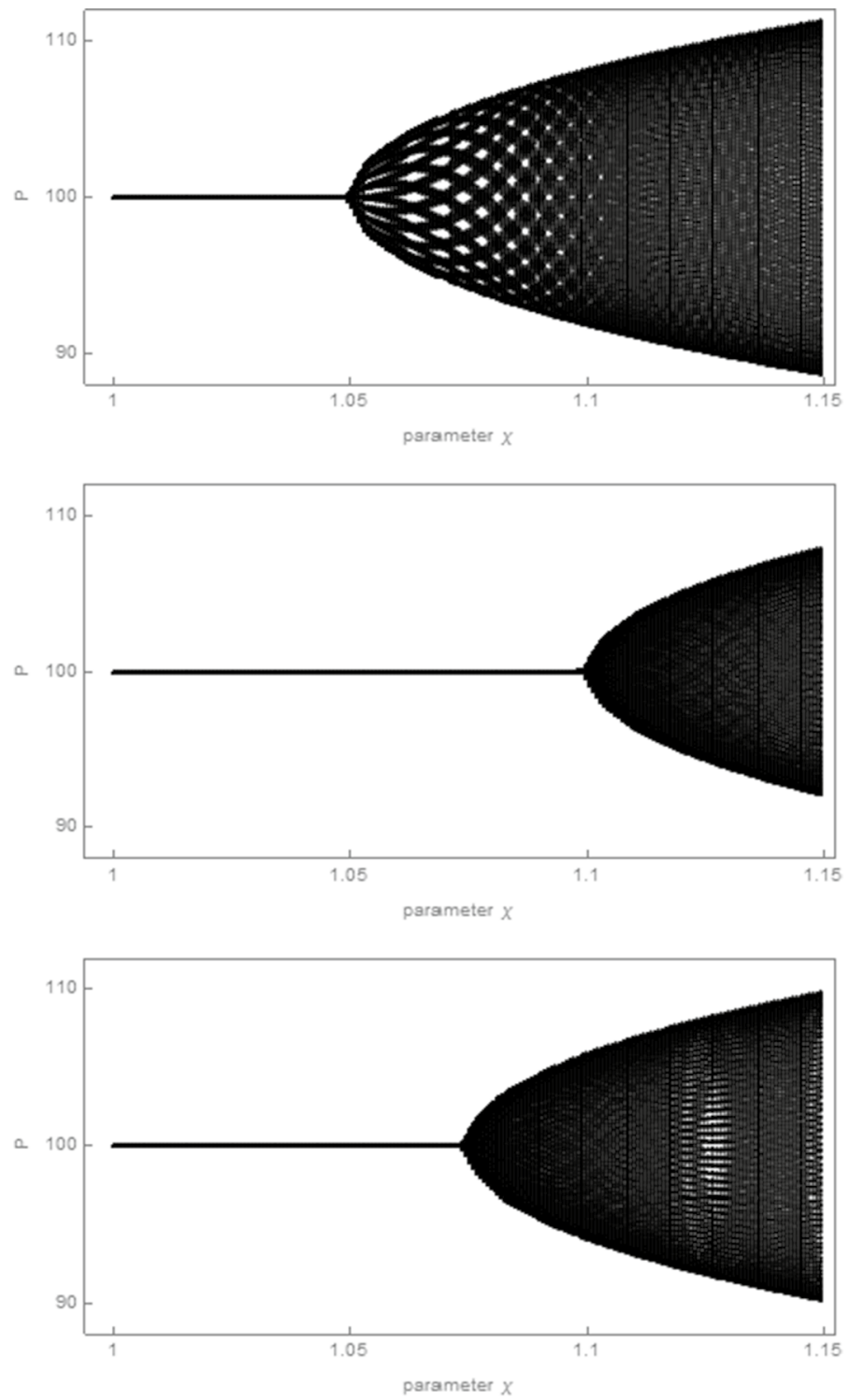

Fig. 2 Effects of homebuyers' extrapolation strength. The panels show bifurcation diagrams of house prices versus homebuyers' extrapolation parameter $\chi$ for flexible rents $(\tau=1)$, fixed rents $(\tau=0)$ and regulated rents $(\tau=0.5)$, respectively. See Sect. 5 for more details on the underlying parameter setting

giving rise to 2,500 grid points, and use $T=1000$ observations to compute the above statistics. Importantly, policymakers can select from the displayed menu. By setting $\tau=0$ and $R^{G}=9$, for instance, policymakers can eliminate house price fluctuations, reduce the average rent level and bring the average rent level close to their target rent level, yet produce significant distortion in the housing market. By setting 

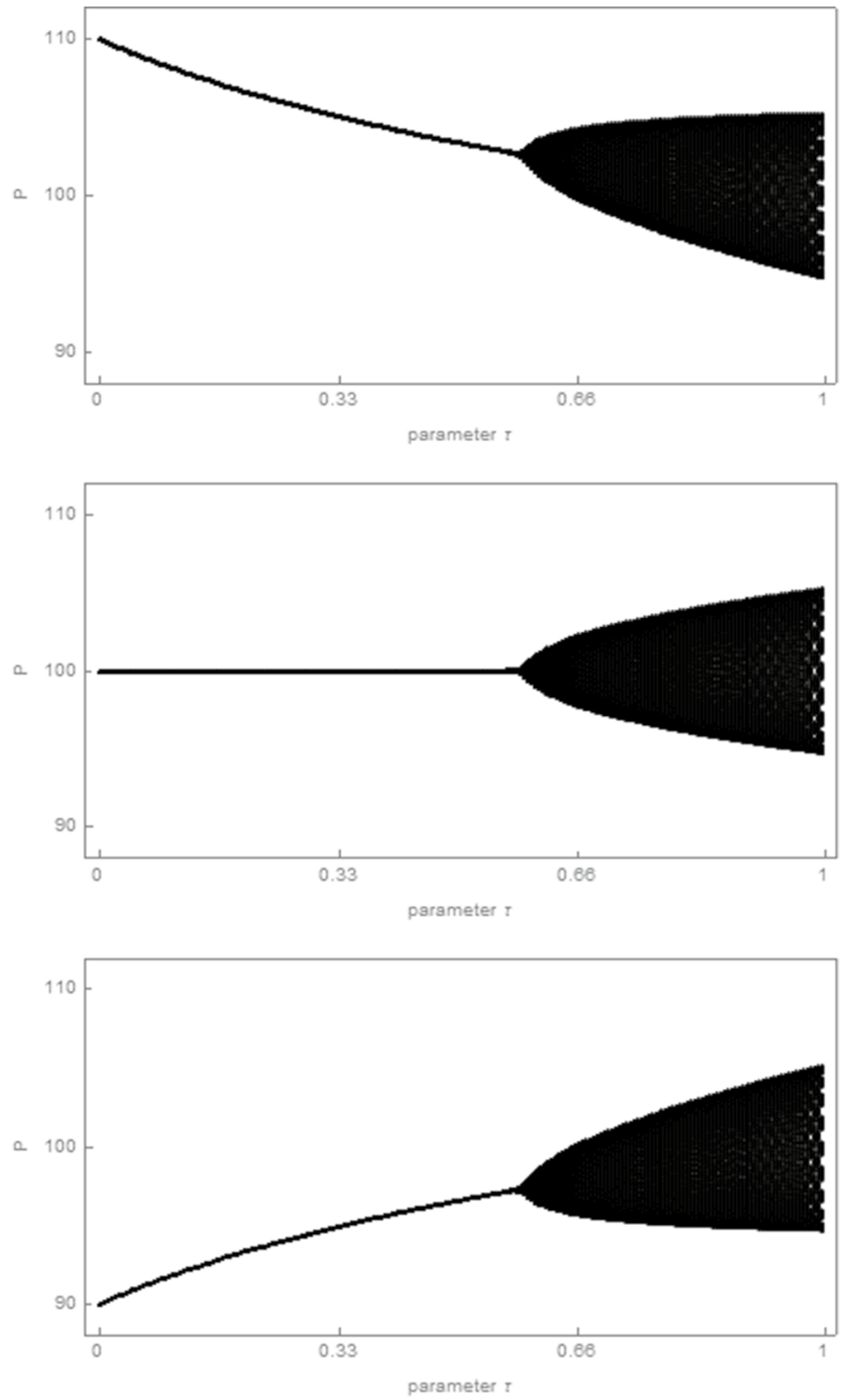

Fig. 3 Effects of policymakers' rent control strength. The panels show bifurcation diagrams of house prices versus policymakers' control parameter $\tau$ for higher target rents $\left(R^{G}=11\right)$, unbiased target rents $\left(R^{G}=10\right)$ and lower target rents $\left(R^{G}=9\right)$. See Sect. 5 for more details on the underlying parameter setting

$\tau=0.5$ and $R^{G}=10$, however, policymakers can reduce the housing market's volatility and distortion. While the average rent level is near the target rent level, the average rent level is higher than in the previous scenario. Clearly, selecting $\tau$ and $R^{G}$ 

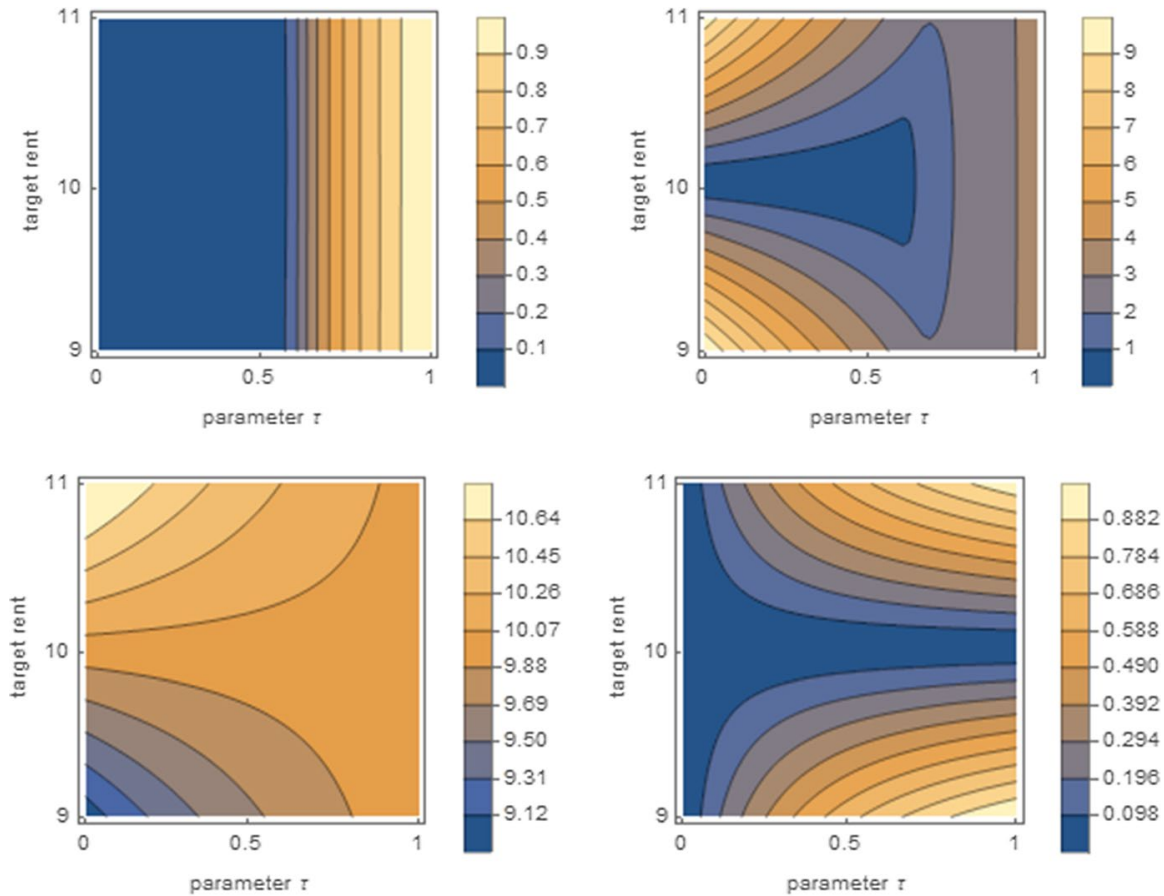

Fig. 4 Joint impact of policymakers' control parameters. The panels show how parameters $\tau$ and $R^{G}$ affect volatility, distortion, the average rent level and the rent level's average absolute deviation from the target rent level, respectively. See Sect. 5 for more details on the underlying parameter setting

is not a scientific task; it is the task of policymakers to choose from this menu, taking into account their policy objectives.

\section{Conclusions}

The reviews by Galbraith (1994), Kindleberger and Aliber (2011) and Glaeser (2013) highlight the fact that housing markets are capable of producing significant boom-bust cycles, often associated with dramatic economic consequences. Since Case and Shiller (2003), Case et al. (2012) and Shiller (2015) report that extrapolative expectations are major drivers of such dynamics, we present a novel housing market model in which homebuyers rely on extrapolative and regressive expectation rules to forecast future house prices. In line with Hommes (2013), homebuyers are capable of learning in the sense that they select expectation rules that have produced lower prediction errors in the past. However, homebuyers also display herding behavior. Our analytical and numerical results reveal that endogenous housing market dynamics is set in motion if homebuyers rely strongly on extrapolative expectations. The house price, the housing stock and the rent level then oscillate around their steady-state values, although there are neither exogenous shocks nor changes in the housing market's fundamentals. 
As it turns out, we can use our model to explore the effectiveness of rent control. Turner and Malpezzi (2003) estimate that around 40-50\% of the world's urban population live in rental housing and that most of these housing units are subject to rent control. The costs and benefits of rent control are a hotly disputed topic among economists. For instance, Metcalf (2018, p. 66) writes that "From the sample of economists that I have known, it appears that opposition to rent control is something like an oath of office." However, Arnot (1995, p. 99) states that there has been a wave of revisionism among economists on the subject of rent control and adds that "Perhaps a majority, at least among the younger generation, would agree with the statement that a welldesigned rent control program can be beneficial." Interestingly, both statements are in line with our results.

A well-designed rent control program in which policymakers set the target rent level equal to the steady-state rent level that would prevail in an unregulated rental market can help to stabilize the housing market, either by preventing the onset of oscillatory housing market dynamics or by decreasing its amplitude. Importantly, such a policy does not create any distortions: the steady-state values of the house price, the housing stock and the rent level correspond to their true fundamental values. However, if policymakers set the target rent level too low, e.g., because they are influenced by certain interest groups (Fallis 1988; Epple 1998), then the house price and the housing stock will decrease as well, an outcome that is usually associated with welfare losses (Glaeser and Luttmer 2003).

Let us conclude our paper by pointing out some possible avenues for future research. In this paper, we assume that policymakers seek to keep the rent level near its target level. However, policymakers may also regulate the rental market in different ways. For instance, policymakers may impose a strict upper boundary for the rent level. Technically speaking, a strict rent ceiling implies that the dynamics of our model would be due to a piecewise-defined map. Avrutin et al. (2019) provide tools to study such dynamical systems. Alternatively, policymakers may place a cap on the maximum allowable percentage change (or increase) in the rent level. Of course, it is important to study rent control programs with other expectations-driven housing markets, too. We hope that our paper stimulates more work in this research direction.

Acknowledgements We thank two anonymous referees for their helpful comments and suggestions.

Funding Open Access funding enabled and organized by Projekt DEAL.

Open Access This article is licensed under a Creative Commons Attribution 4.0 International License, which permits use, sharing, adaptation, distribution and reproduction in any medium or format, as long as you give appropriate credit to the original author(s) and the source, provide a link to the Creative Commons licence, and indicate if changes were made. The images or other third party material in this article are included in the article's Creative Commons licence, unless indicated otherwise in a credit line to the material. If material is not included in the article's Creative Commons licence and your intended use is not permitted by statutory regulation or exceeds the permitted use, you will need to obtain permission directly from the copyright holder. To view a copy of this licence, visit http://creativecommons.org/licen ses/by/4.0/. 


\section{Appendix A}

Introducing the auxiliary variables $X_{t}=P_{t-1}, Y_{t}=X_{t-1}$ and $Z_{t}=Y_{t-1}$ allows us to express our model by the six-dimensional nonlinear map

$$
T:\left\{\begin{array}{l}
P_{t}=\frac{P_{t-1}+W_{t}^{E} \eta \arctan \left[\frac{\chi}{\eta}\left(P_{t-1}-X_{t-1}\right)\right]+\left(1-W_{t}^{E}\right) \phi\left(F-P_{t-1}\right)+R^{G}+\tau\left(\alpha-\beta H_{t}-R^{G}\right)}{1+r+\delta} \\
X_{t}=P_{t-1} \\
Y_{t}=X_{t-1} \\
Z_{t}=Y_{t-1} \\
H_{t}=\gamma P_{t-1}+(1-\delta) H_{t-1} \\
W_{t}^{E}=\frac{W_{t-1}^{E}}{W_{t-1}^{E}+\left(1-W_{t-1}^{E}\right) \exp \left[\varepsilon\left(A_{t}^{R}-A_{t}^{E}\right)\right]}
\end{array}\right.
$$

where $A_{t}^{R}-A_{t}^{E}=\mu\left\{\left(P_{t-1}-Y_{t-1}-\eta \arctan \left[\frac{\chi}{\eta}\left(Y_{t-1}-Z_{t-1}\right)\right]\right)^{2}-\left(P_{t-1}-Y_{t-1}-\phi\left(F-Y_{t-1}\right)\right)^{2}\right\}-\sigma$.

By imposing the steady-state conditions on (A1), one easily obtains two (boundary) steady states, namely $S_{1}=\left(\bar{P}, \bar{P}, \bar{P}, \bar{P}, \frac{\gamma}{\delta} \bar{P}, 1\right)$, where $\bar{P}=\frac{\left((1-\tau) R^{G}+\tau \alpha\right) \delta}{(r+\delta) \delta+\tau \beta \gamma}$, and $S_{2}=\left(\bar{P}, \bar{P}, \bar{P}, \bar{P}, \frac{\gamma}{\delta} \bar{P}, 0\right)$, where $\bar{P}=\frac{\left((1-\tau) R^{G}+\tau \alpha+\phi F\right) \delta}{(r+\delta+\phi) \delta+\tau \beta \gamma}$. In order to check for their local asymptotic stability, we have to compute the Jacobian matrix, derive the characteristic polynomial, i.e., $\mathcal{P}(\lambda)=\operatorname{det}(J-\lambda I)$ and determine whether the corresponding eigenvalues are less than one in modulus.

For the steady state $S_{1}$, we obtain

$$
J\left(S_{1}\right)=\left(\begin{array}{llllll}
\frac{1-\tau \beta \gamma+\chi}{1+r+\delta} & -\frac{\chi}{1+r+\delta} & 0 & 0 & -\frac{\beta(1-\delta) \gamma}{1+r+\delta} & -\frac{\exp \left[\varepsilon\left(-\sigma-\mu(F-\bar{P})^{2} \phi^{2}\right)\right](F-\bar{P}) \phi}{1+r+\delta} \\
1 & 0 & 0 & 0 & 0 & 0
\end{array}\right.
$$

yielding

$$
\mathcal{P}(\lambda)=(0-\lambda)^{2}\left\{\exp \left[\varepsilon\left(-\sigma-\mu(F-\bar{P})^{2} \phi^{2}\right)\right]-\lambda\right\} \mathcal{P}_{3}(\lambda) .
$$

The third-degree polynomial $\mathcal{P}_{3}(\lambda)$ is the characteristic polynomial of the three-dimensional submatrix

$$
A=\left(\begin{array}{lll}
\frac{1-\tau \beta \gamma+\chi}{1+r+\delta} & -\frac{\chi}{1+r+\delta} & -\frac{\beta(1-\delta) \gamma}{1+r+\delta} \\
1 & 0 & 0 \\
\gamma & 0 & 1-\delta
\end{array}\right),
$$


given by

$$
\mathcal{P}_{3}(\lambda)=\lambda^{3}+a_{1} \lambda^{2}+a_{2} \lambda+a_{3}=0,
$$

where $a_{1}=\frac{-2+r(\delta-1)+\delta^{2}+\tau \beta \gamma-\chi}{1+r+\delta}, a_{2}=\frac{1+2 \chi-\delta(1+\chi)}{1+r+\delta}$ and $a_{3}=\frac{(\delta-1) \chi}{1+r+\delta}$.

From $(A 3)=0$, we can conclude that two eigenvalues, say $\lambda_{1}$ and $\lambda_{2}$, are equal to zero, while $\lambda_{3}=\exp \left[\varepsilon\left(-\sigma-\mu(F-\bar{P})^{2} \phi^{2}\right)\right]$. Since $-\sigma-\mu(F-\bar{P})^{2} \phi^{2}<0$ and $\varepsilon>0$, it is clear that $0<\lambda_{3}<1$, implying that the stability properties of (A2) are fully determined by the third-degree characteristic polynomial (A5). We follow Lines et al. (2020) and Gardini et al. (2020), who provide a simplified set of stability conditions for such a polynomial, to study the stability of steady state $S_{1}$. From (i) $1+a_{1}+a_{2}+a_{3}>0$, (ii) $1-a_{1}+a_{2}-a_{3}>0$ and (iii) $1-a_{2}+a_{1} a_{3}-a_{3}^{2}>0$, we obtain

$$
\begin{gathered}
\delta(r+\delta)+\tau \beta \gamma>0 \\
\tau \beta \gamma+\delta(r+\delta)<4+2 r+2 \chi(2-\delta)
\end{gathered}
$$

and

$$
\chi<1+r+\delta-\tau \frac{\beta \gamma(1-\delta) \chi}{r+\delta(2-\chi(1-\delta))},
$$

whose violation is associated with a Fold, Flip and Neimark-Sacker bifurcation, respectively. As we have $0<\delta<1, \beta>0, \gamma>0$ and $0 \leq \tau \leq 1$, condition (i) is always satisfied. Thus, steady state $S_{1}$ loses its local asymptotic stability if inequality (ii) or (iii) is violated.

Computing the Jacobian matrix at the steady state $S_{2}$, i.e.

$$
J\left(S_{2}\right)=\left(\begin{array}{llllll}
\frac{1-\tau \beta \gamma-\phi}{1+\gamma+\delta} & 0 & 0 & 0 & -\frac{\beta(1-\delta) \gamma}{1+r+\delta} & -\frac{\exp \left[-\varepsilon\left(-\sigma-\mu(F-\bar{P})^{2} \phi^{2}\right)\right](F-\bar{P}) \phi}{1+r+\delta} \\
1 & 0 & 0 & 0 & 0 & 0 \\
0 & 1 & 0 & 0 & 0 & 0 \\
0 & 0 & 1 & 0 & 0 & 0 \\
\gamma & 0 & 0 & 0 & 1-\delta & 0 \\
0 & 0 & 0 & 0 & 0 & \\
0 & & & &
\end{array}\right.
$$

yields

$$
\mathcal{P}(\lambda)=(0-\lambda)^{2}\left\{\exp \left[-\varepsilon\left(-\sigma-\mu(F-\bar{P})^{2} \phi^{2}\right)\right]-\lambda\right\} \mathcal{P}_{3}(\lambda),
$$

where $\mathcal{P}_{3}(\lambda)$ is again the characteristic polynomial obtained from a submatrix, given by 


$$
B=\left(\begin{array}{ccc}
\frac{1-\tau \beta \gamma-\phi}{1+r+\delta} & 0 & -\frac{\beta(1-\delta) \gamma}{1+r+\delta} \\
1 & 0 & 0 \\
\gamma & 0 & 1-\delta
\end{array}\right)
$$

By setting (A7) equal to zero, it becomes clear that we again have two eigenvalues equal to zero, i.e., $\lambda_{1,2}=0$, and one eigenvalue, say $\lambda_{3}$, given by

$$
\lambda_{3}=\exp \left[-\varepsilon\left(-\sigma-\mu(F-\bar{P})^{2} \phi^{2}\right)\right] \text {. However, it is always the case that }
$$

$\lambda_{3}>1$, since $-\varepsilon\left(-\sigma-\mu(F-\bar{P})^{2} \phi^{2}\right)>0$, implying that steady state $S_{2}$ is unstable.

\section{Appendix B}

If information costs are positive, all homebuyers rely on the extrapolative expectation rule at the model's economically meaningful steady state. In this appendix, we briefly discuss the nongeneric, yet interesting case in which homebuyers have free access to the true fundamental house price, i.e., $\sigma=0$ and $F=\bar{P}$. While it still follows that $\bar{P}=\frac{\left((1-\tau) R^{G}+\tau \alpha\right) \delta}{(r+\delta) \delta+\tau \beta \gamma}, \bar{H}=\frac{\gamma}{\delta} \bar{P}$ and $\bar{R}=(r+\delta) \bar{P}, \bar{W}^{E}$ and $\bar{W}^{R}$ become indeterminate. To see this, note that neither the extrapolative expectation rule nor the regressive expectation rule produces any prediction errors at this steady state and, consequently, their evolutionary fitness is identical and equal to zero. Moreover, whether the housing market settles on its fundamental steady state or displays endogenous cyclical dynamics depends not only on the model's parameters, but also on its initial conditions.

For instance, initial conditions may favor the use of the extrapolative expectation rule, keeping the dynamics of the housing market alive. Such a scenario is depicted in the left panels of Fig. 5, based on our standard parameter setting, except that $\chi=1.15, \sigma=0$ and $\tau=1$, showing the evolution of house prices, market shares of the extrapolative expectation rule and differences in the evolutionary fitness of the two expectation rules, respectively. Once the housing market starts to display cyclical dynamics, the extrapolative expectation rule tends to outperform the regressive expectation rule, and the housing market continues its oscillatory behavior. In this respect, it seems worthwhile to recall that Case and Shiller (2003), Case et al. (2012) and Shiller (2015) report that homebuyers' extrapolative expectations are in fact major drivers of actual house price dynamics, an observation that fits nicely with one of our main model predictions.

However, a different set of initial conditions may favor the use of the regressive expectation rule, pushing the house price toward its fundamental value, as visible in the right panels of Fig. 5. Here, we have an example in which the market share of the extrapolative expectation rule eventually settles on a value of about 30 percent, though we may observe similar scenarios where the market share of the extrapolative expectation rule settles on a higher or a lower value. One other comment is 

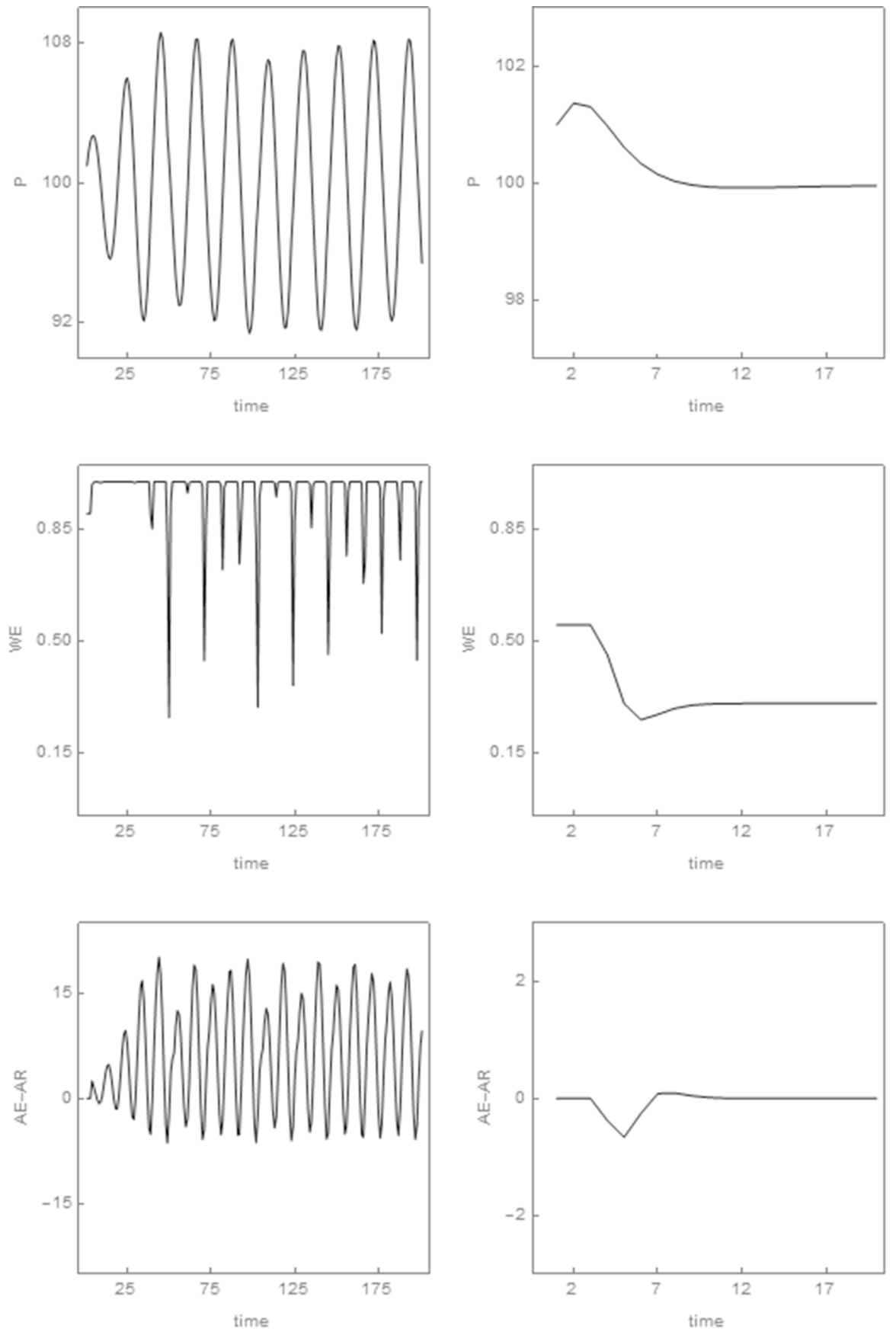

Fig. 5 Free access to the fundamental house price. The left panels show the evolution of house prices, market shares of the extrapolative expectation rule and differences in the evolutionary fitness of the two expectation rules, respectively. The right panels show the same for a different set of initial conditions. See Appendix B for more details on the underlying parameter setting 
in order. In the presence of exogenous shocks, our model may produce interesting attractor switching dynamics, e.g., periods in which the house price displays significant cycles and periods in which the house price is close to its fundamental value. We believe that such model implications deserve greater attention in future work.

\section{Appendix C}

Rent control policy (9) regulates the rental market whenever the rent level deviates from the policymakers' target rent level. However, policymakers may prefer a rent control policy that only becomes effective when the rent level is about to exceed a critical rent level. Such a rent control policy may be specified by

$$
R_{t}= \begin{cases}(1-\tau) R^{G}+\tau\left(\alpha-\beta H_{t}\right) & \text { if } R^{G}<\alpha-\beta H_{t} \\ \alpha-\beta H_{t} & \text { otherwise }\end{cases}
$$

with $R^{G}>0$ and $0 \leq \tau \leq 1$ as control parameters. Note that $(\mathrm{C} 1)$ regulates the rental market in the same way as (9) does if the unregulated rent level exceeds policymakers' target rent level. Otherwise, it leaves the rental market unregulated.

Figure 6 illustrates some effects of rent control policy (C1). The top panel shows a bifurcation diagram of house prices versus homebuyers' extrapolation parameter $\chi$, assuming our base parameter setting, except that $R^{G}=10.1$ and $\tau=0.2$. Note that Proposition 1 is still helpful to characterize our model. As long as the rent level stays below $R^{G}=10.1$, the rental market is de facto unregulated (we can thus use $\tau=1$ to evaluate Proposition 1's predictions). Hence, the model's fundamental steady state, implying, among other things, that $\bar{P}=100, \bar{H}=100$ and $\bar{R}=10$, becomes unstable due to a Neimark-Sacker bifurcation as parameter $\chi$ exceeds $\chi_{\text {crit }}^{N S} \approx 1.051$. At about $\chi \approx 1.08$, however, the amplitude of the rent cycles starts to exceed $R^{G}=10.1$. From then on, the rental market is periodically regulated. Note furthermore that the fluctuations of the rent level become asymmetric. In particular, rent control policy (C1) manages to prevent the emergence of relatively high rent levels and occasionally produces relatively low rent levels, an outcome that may be in the interest of policymakers. The bifurcation diagram depicted in the bottom panel rests on $R^{G}=9$ .95 , implying that $\bar{P}=99.66, \bar{H}=99.66$ and $\bar{R}=9.66$. Since the rental market is always regulated at this steady state, we can again apply Proposition 1 and compute the occurrence of a Neimark-Sacker bifurcation at $\chi_{\text {crit }}^{N S} \approx 1.089$. Note that for $\chi>1.11$, there are periods where the rental market is not regulated because the rent level falls below $R^{G}=9.95$. The central panel of Fig. 6 , based on $R^{G}=10$, shows an intermediate scenario. We numerically observe that the housing market starts to display endogenous dynamics as parameter $\chi$ exceeds $\chi_{\text {crit }}^{N S} \approx 1.07$ and find that rent control policy $(\mathrm{C} 1)$ again helps to limit the rent level. 

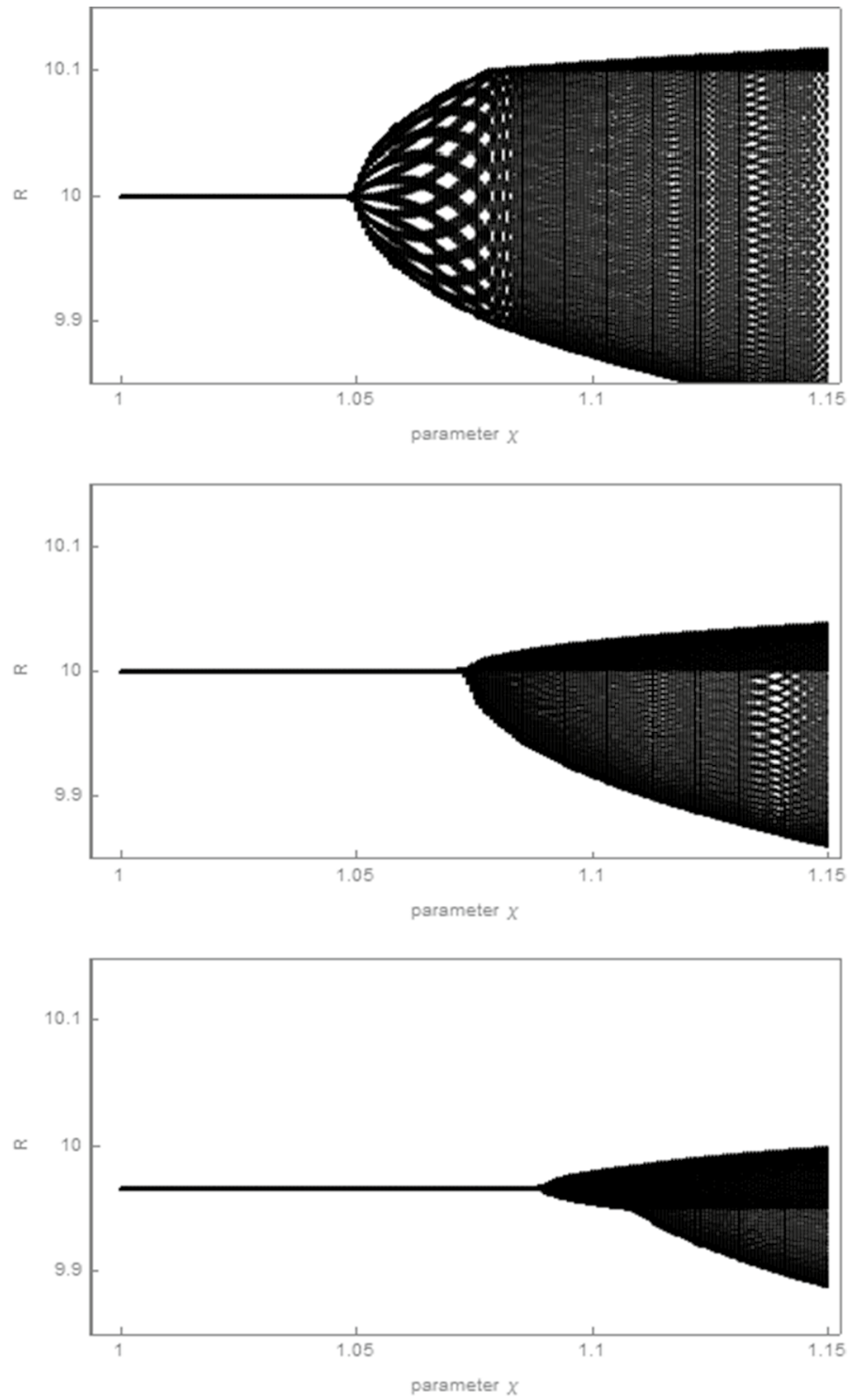

Fig. 6 Effects of an alternative rent control policy. The panels show bifurcation diagrams of house prices versus homebuyers' extrapolation parameter $\chi$ for higher target rents $\left(R^{G}=10.1\right)$, unbiased target rents $\left(R^{G}=10\right)$ and lower target rents $\left(R^{G}=9.95\right)$, respectively. See Appendix $\mathrm{C}$ for more details on the underlying parameter setting

\section{References}

Anufriev M, Bao T, Tuinstra J (2016) Microfoundations for switching behavior in heterogeneous agent models: an experiment. J Econ Behav Organ 129:74-99 
Anufriev M, Chernulich A, Tuinstra J (2018) A laboratory experiment on the heuristic switching model. J Econ Dyn Control 91:21-42

Arnot R (1995) Time for revisionism on rent control? J Econ Perspect 9:99-120

Autor D, Palmer C, Pathak P (2014) Housing market spillovers: evidence from the end of rent control in Cambridge, Massachusetts. J Polit Econ 122:661-717

Avrutin V, Gardini L, Schanz M, Sushko I, Tramontana F (2019) Continuous and discontinuous piecewise-smooth one-dimensional maps: invariant sets and bifurcation structures. World Scientific, Singapore

Bao T, Hommes C (2019) When speculators meet suppliers: positive versus negative feedback in experimental housing markets. J Econ Dyn Control 107:103730

Bischi G, Lamantia F, Radi D (2015) An evolutionary Cournot model with limited market knowledge. J Econ Behav Organ 116:219-238

Bolt W, Demertzis M, Diks C, Hommes C, van der Leij M (2019) Identifying booms and busts in house prices under heterogeneous expectations. J Econ Dyn Control 103:234-259

Brock W, Hommes C (1997) A rational route to randomness. Econometrica 65:1059-1095

Brock W, Hommes C (1998) Heterogeneous beliefs and routes to chaos in a simple asset pricing model. J Econ Dyn Control 22:1235-1274

Burnside C, Eichenbaum M, Rebelo S (2016) Understanding booms and busts in housing markets. J Polit Econ 124:1088-1147

Campisi G, Naimzada A, Tramontana F (2018) Local and global analysis of a speculative housing market with production lag. Chaos 28:055901

Case K, Shiller R (2003) Is there a bubble in the housing market? Brook Pap Econ Act 2:299-362

Case K, Shiller R, Thompson A (2012) What have they been thinking? Homebuyer behavior in hot and cold markets. Brook Pap Econ Act 2:265-298

Chiarella C (1992) The dynamics of speculative behavior. Ann Oper Res 37:101-123

Chiarella C, He X-Z, Hommes C (2006) A dynamic analysis of moving average rules. J Econ Dyn Control 30:1729-1753

Day R, Huang W (1990) Bulls, bears and market sheep. J Econ Behav Organ 14:299-329

De Grauwe P, Dewachter H, Embrechts M (1993) Exchange rate theory-chaotic models of foreign exchange markets. Blackwell, Oxford

Dieci R, He X-Z (2018) Heterogeneous agent models in finance. In: Hommes C, LeBaron B (eds) Handbook of computational economics: heterogeneous agent modeling. North-Holland, Amsterdam, pp $257-328$

Dieci R, Westerhoff F (2012) A simple model of the speculative housing market. J Evol Econ 22:303-329

Dieci R, Westerhoff F (2013) Modeling house price dynamics with heterogeneous speculators. In: Bischi GI, Chiarella C, Sushko I (eds) Global dynamics in economics and finance. Essays in honour of Laura Gardini. Springer, Berlin, pp 35-61

Dieci R, Westerhoff F (2016) Heterogeneous expectations, boom-bust housing cycles, and supply conditions: a nonlinear economic dynamics approach. J Econ Dyn Control 71:21-44

Diks C, Wang J (2016) Can a stochastic cusp catastrophe model explain housing market crashes? J Econ Dyn Control 69:68-88

Dindo P, Tuinstra J (2011) A class of evolutionary models for participation games with negative feedback. Comput Econ 37:267-300

Eichholtz P, Huisman R, Zwinkels R (2015) Fundamentals or trends? A long-term perspective on house prices. Appl Econ 47:1050-1059

Epple D (1998) Rent control versus reputation: theory and evidence. Reg Sci Urban Econ 28:679-710

Fallis G (1988) Rent control: the citizen, the market, and the state. J Real Estate Finance Econ 1:309-320

Galbraith JK (1994) A short history of financial euphoria. Penguin Books, London

Gardini L, Schmitt N, Sushko I, Tramontana F, Westerhoff F (2020) Necessary and sufficient conditions for the roots of a cubic polynomial and bifurcations of codimension-1, $-2,-3$ for 3D maps. Working paper series in economics, mathematics and statistics, \# 2019/08, University of Urbino

Glaeser E (2013) A nation of gamblers: real estate speculation and American history. Am Econ Rev 103:1-42

Glaeser E, Luttmer E (2003) The misallocation of housing under rent control. Am Econ Rev 93:1027-1046

Glaeser E, Nathanson C (2017) An extrapolative model of house price dynamics. J Financ Econ 126:147-170 
He X-Z, Westerhoff F (2005) Commodity markets, price limiters and speculative price dynamics. J Econ Dyn Control 29:1577-1596

Hofbauer J, Sigmund K (1988) The theory of evolution and dynamical systems. Cambridge University Press, Cambridge

Hofbauer J, Weibull J (1996) Evolutionary selection against dominated strategies. J Econ Theory 71:558-573

Hommes C (2011) The heterogeneous expectations hypothesis: some evidence from the lab. J Econ Dyn Control 35:1-24

Hommes C (2013) Behavioral rationality and heterogeneous expectations in complex economic systems. Cambridge University Press, Cambridge

Kindleberger C, Aliber R (2011) Manias, panics, and crashes: a history of financial crises. Wiley, Hoboken

Kopel M, Lamantia F, Szidarovszky F (2014) Evolutionary competition in a mixed market with socially concerned firms. J Econ Dyn Control 48:394-409

Kouwenberg R, Zwinkels R (2014) Forecasting the US housing market. Int J Forecast 30:415-425

Lines M, Schmitt N, Westerhoff F (2020) Stability conditions for three-dimensional maps and their associated bifurcation types. Appl Econ Lett 27:1056-1060

Martin C, Schmitt N, Westerhoff F (2020a) Housing markets, expectation formation and interest rates. Macroecon Dyn (in press)

Martin C, Schmitt N, Westerhoff F (2020b) Heterogeneous expectations, housing bubbles and tax policy. $\mathrm{J}$ Econ Behav Organ (in press)

Menkhoff L, Taylor M (2007) The obstinate passion of foreign exchange professionals: technical analysis. J Econ Lit 45:936-972

Metcalf G (2018) Sand castles before the tide? Affordable housing in expensive cities. J Econ Perspect 32:59-80

Poterba J (1984) Tax subsidies to owner-occupied housing: an asset market approach. Q J Econ 99:729-752

Poterba J (1991) House price dynamics: the role of tax policy and demography. Brook Pap Econ Act 2:143-203

Schmitt N, Westerhoff F (2019) Short-run momentum, long-run mean reversion and excess volatility: an elementary housing model. Econ Lett 176:43-46

Schmitt N, Westerhoff F (2020) Pricking asset market bubbles. Finance Res Lett (in press)

Schmitt N, Tuinstra J, Westerhoff F (2017) Side effects of nonlinear profit taxes in a behavioral market entry model: abrupt changes, coexisting attractors and hysteresis problems. J Econ Behav Organ $135: 15-38$

Shiller R (2015) Irrational exuberance. Princeton University Press, Princeton

Sims D (2007) Out of control: what can we learn from the end of Massachusetts rent control? J Urban Econ 61:129-151

Turner B, Malpezzi S (2003) A review of empirical evidence on the costs and benefits of rent control. Swed Econ Policy Rev 10:11-56 